\title{
Carbon Nanotube Addition to Simultaneously Enhance Strength and Ductility of Hybrid AZ31/AA5083 Alloy
}

\author{
Muralidharan Paramsothy ${ }^{1}$, Manoj Gupta ${ }^{1 *}$, Jimmy Chan ${ }^{2}$, Richard Kwok ${ }^{2}$ \\ ${ }^{1}$ Department of Mechanical Engineering, National University of Singapore, Kent Ridge, Singapore; ${ }^{2}$ Singapore Technologies Kinet- \\ ics Ltd (ST Kinetics), Boon Lay, Singapore. \\ Email: mpegm@nus.edu.sg
}

Received December $13^{\text {th }}, 2010$; revised January $4^{\text {th }}, 2011$; accepted January $10^{\text {th }}, 2011$.

\begin{abstract}
AZ31/AA5083 hybrid alloy nanocomposite containing CNT nanoparticle reinforcement was fabricated using solidification processing followed by hot extrusion. The AZ31/AA5083 hybrid alloy nanocomposite exhibited similar grain size to monolithic AZ31/AA5083 hybrid alloy, reasonable CNT nanoparticle distribution, non-dominant $\left(\begin{array}{llll}0 & 0 & 2\end{array}\right)$ texture in the longitudinal direction, and 20\% higher hardness than monolithic AZ31/AA5083 hybrid alloy. Compared to monolithic AZ31/AA5083 hybrid alloy (in tension), the AZ31/AA5083 hybrid alloy nanocomposite exhibited higher $0.2 \%$ TYS, UTS, failure strain and work of fracture (WOF) $(+9 \%,+4 \%,+38 \%$ and $+44 \%$, respectively). Also, compared to monolithic AZ31/AA5083 hybrid alloy (in compression), the AZ31/AA5083 hybrid alloy nanocomposite exhibited similar $0.2 \%$ CYS $(+1 \%)$, and higher UCS, failure strain and WOF $(+7 \%,+23 \%$ and $+23 \%$, respectively). The effect of CNT nanoparticle addition on the enhanced tensile and compressive response of AZ31/AA5083 hybrid alloy is investigated in this paper.
\end{abstract}

Keywords: AZ31/AA5083 Hybrid Alloy, Carbon Nanotube Nanocomposite, Microstructure, Mechanical Properties

\section{Introduction}

AZ31 is a very commonly used Al-containing (or Zr-free) $\mathrm{Mg}$ alloy in today's engineering world. Its use comes with the following engineering advantages: 1) Low cost, 2) Ease of handling and 3) Good strength and ductility. Using the friction stir processing technique recently, AZ31 has been surface-reinforced with $\mathrm{SiC}$ microparticulates [1], $\mathrm{C}_{60}$ molecules [2], and multi-walled carbon nanotubes [3]. Here, it was reported that the base matrix was consequently hardened due to good dispersion. Similar findings along with grain refinement were also reported for $\mathrm{AZ} 31$ reinforced with $\mathrm{SiC}$ and $\mathrm{B}_{4} \mathrm{C}$ microparticulates using gas-tungsten arc (GTA) with simultaneous reinforcement powder feeding processing technique [4-6]. Adherent and defect-free particle-matrix interface in the $\mathrm{AZ} 31 / \mathrm{SiC}$ microcomposite has been reported $[5,6]$. Pulsed current hot pressing (PCHP) has been used to incorporate TiNi shape memory alloy (SMA) fibers in AZ31 matrix without significant interfacial reaction [7]. The yield stress and elongation in the AZ31/TiNi microcomposite increased with temperature (strength significantly exceeded that of AZ31 matrix). This was a consequence of residual compressive stress in the AZ31 matrix due to phase change induced shrinkage of the TiNi fiber. Technically, AZ31 may be alloyed with more pure aluminium to obtain the other magnesium alloys in the AZ series (AZ61, AZ81, AZ91 etc.). However, the use of aluminium alloy (as opposed to pure aluminium) to metallurgically upgrade AZ31 has not been reported. There may be certain advantages in this approach based on the lower liquidus temperature of the aluminium alloy compared to pure aluminium. The carbon nanotube (CNT) possesses many unique properties $[8,9]$ which enable it to be useful in selected applications. It has superior strength $(30 \mathrm{GPa})$ and stiffness $(1 \mathrm{TPa})$ in tension [10]. Also, the CNT bends reversibly [11]. Its electrical properties are comparable to those of metals and semi-conductors $[12,13]$. Furthermore, the thermal conductivity of the CNT has been predicted to be unusually high [14]. Additionally, the CNT has a high aspect ratio which implies that it has a high surface area to volume ratio [15]. The unique properties and high SA/V ratio of the CNT have resulted in its combination with 
other materials in attempts to create useful composite materials [16-19]. However, open literature search has revealed that no successful attempt has been made to simultaneously increase tensile as well as compressive strength and ductility of wrought AZ31/AA5083 hybrid alloy with well dispersed CNT or any other nanoparticles, using a high volume production spray-deposition based solidification processing technique.

Accordingly, the primary aim of this study was to simultaneously increase strength and ductility in tension and compression of wrought AZ31/AA5083 hybrid alloy using CNT as reinforcement. Disintegrated melt deposition (DMD) $[20,21]$ followed by hot extrusion was used to synthesize the wrought AZ31/AA5083/CNT hybrid alloy nanocomposite.

\section{Experimental Procedures}

\subsection{Materials}

In this study, AZ31 (nominally 2.50-3.50 wt.\% Al, 0.60-1.40 wt.\% Zn, 0.15-0.40 wt.\% Mn, 0.10 wt.\% Si, 0.05 wt.\% $\mathrm{Cu}, 0.01$ wt.\% Fe, 0.01 wt.\% Ni, balance $\mathrm{Mg}$ ), supplied by Tokyo Magnesium Co. Ltd. (Yokohama, Japan) was used as shell matrix material. AA5083 (nominally 4.0-4.9 wt.\% Mg, 0.40 wt.\% Si, 0.40 wt.\% Fe, 0.10 wt. $\% \mathrm{Cu}, 0.40-1.00$ wt. $\% \mathrm{Mn}, 0.05-0.25$ wt.\% Cr, 0.25 wt. $\%$ Zn, 0.15 wt. $\%$ Ti, 0.15 wt. $\%$ others, balance Al), supplied by Yan San Metals Pte. Ltd. (Singapore) was used (addition of $3 \mathrm{wt} . \%$ relative to AZ31 weight) to metallurgically upgrade AZ31. AZ31 and AA5083 blocks were sectioned to smaller pieces. All oxide and scale surfaces were removed using machining. All surfaces were washed with ethanol after machining. CNT powder (vapor grown, 94.7\% purity, 40-70 nm outer diameter, up to 100 aspect ratio [22]) supplied by Nanostructured \& Amorphous Materials Inc (Texas, USA) was used as the reinforcement phase.

\subsection{Processing}

Monolithic AZ31/AA5083 hybrid alloy (3 wt.\% AA 5083 addition relative to AZ31 weight) was cast using the DMD method [20,21]. This involved heating AZ31 and AA5083 blocks to $750^{\circ} \mathrm{C}$ in an inert Ar gas atmosphere in a graphite crucible using a resistance heating furnace. The crucible was equipped with an arrangement for bottom pouring. Upon reaching the superheat temperature, the molten slurry was stirred for $2.5 \mathrm{~min}$ at 460 rpm using a twin blade (pitch $45^{\circ}$ ) mild steel impeller to facilitate the uniform distribution of heat. The impeller was coated with $\mathrm{Zirtex} 25\left(86 \% \mathrm{ZrO}_{2}, 8.8 \% \mathrm{Y}_{2} \mathrm{O}_{3}, 3.6 \%\right.$ $\mathrm{SiO}_{2}, 1.2 \% \mathrm{~K}_{2} \mathrm{O}$ and $\mathrm{Na}_{2} \mathrm{O}$, and $0.3 \%$ trace inorganics) to avoid iron contamination of the molten metal. The melt was then released through a $10 \mathrm{~mm}$ diameter orifice at the base of the crucible. The melt was disintegrated by two jets of argon gas oriented normal to the melt stream located $265 \mathrm{~mm}$ from the melt pouring point. The argon gas flow rate was maintained at $25 \mathrm{lpm}$. The disintegrated melt slurry was subsequently deposited onto a metallic substrate located $500 \mathrm{~mm}$ from the disintegration point. An ingot of $40 \mathrm{~mm}$ diameter was obtained following the deposition stage. To form the AZ31/ AA5083/1.0 vol.\% CNT hybrid alloy nanocomposite, CNT powder was isolated by wrapping in Al foil of minimal weight $(<0.50$ wt.\% with respect to AZ31 and AA5083 total matrix weight) and arranged on top of the AZ31 and AA5083 alloy blocks, with all other DMD parameters unchanged. All billets were machined to 35 $\mathrm{mm}$ diameter and hot extruded using 20.25:1 extrusion ratio on a 150 ton hydraulic press. The extrusion temperature was $350^{\circ} \mathrm{C}$. The billets were held at $400^{\circ} \mathrm{C}$ for $60 \mathrm{~min}$ in a furnace prior to extrusion. Colloidal graphite was used as a lubricant. Rods of $8 \mathrm{~mm}$ were obtained.

\subsection{Heat Treatment}

Heat treatment was carried out on all extruded sections at $200^{\circ} \mathrm{C}$ for 1 hour using a resistance heating furnace. This selection of temperature and time was made in order to relax the monolithic AZ31/AA5083 hybrid alloy (3 wt.\% AA5083 addition relative to AZ31 weight) without recrystallization softening. The recrystallization temperature of AZ61 magnesium alloy (as the nearest matching alloy in terms of composition) following $20 \%$ cold work after 1 hour is $288^{\circ} \mathrm{C}$ [23]). Prior to heat treatment, the sections were coated with colloidal graphite and wrapped in aluminum foil to minimize reaction with oxygen present in the furnace atmosphere.

\subsection{Microstructural Characterization}

Microstructural characterization studies were conducted on metallographically polished monolithic and nanocomposite extruded samples to determine grain characteristics as well as nanoparticle reinforcement distribution. Hitachi S4300 Field-Emission SEM was used. Image analysis using Scion software was carried out to determine the grain characteristics. XRD studies were conducted using $\mathrm{CuK}_{\alpha}$ radiation $(\lambda=1.5406 \AA)$ with a scan speed of $2 \%$ min in an automated Shimadzu LAB-X XRD-6000 diffractometer to determine intermetallic phase(s) presence and dominant textures in the transverse and longitudinal (extrusion) directions.

\subsection{Hardness}

Microhardness measurements were made on polished monolithic and nanocomposite extruded samples. Vickers microhardness was measured using Matsuzawa MXT50 automatic digital microhardness tester using 25 
gf-indenting load and $15 \mathrm{~s}$ dwell time.

\subsection{Tensile Testing}

Smooth bar tensile properties of the monolithic and nanocomposite extruded samples were determined based on ASTM E8M-05. Round tension test samples of $5 \mathrm{~mm}$ diameter and $25 \mathrm{~mm}$ gauge length were subjected to tension using an MTS 810 machine equipped with an axial extensometer with a crosshead speed set at $0.254 \mathrm{~mm} / \mathrm{min}$. Fractography was performed on the tensile fracture surfaces using Hitachi S4300 FESEM.

\subsection{Compressive Testing}

Compressive properties of the monolithic and nanocomposite extruded samples were determined based on ASTM E9-89a. Samples of $8 \mathrm{~mm}$ length (1) and $8 \mathrm{~mm}$ diameter (d) where $1 / \mathrm{d}=1$ were subjected to compression using a MTS 810 machine with $0.005 \mathrm{~min}^{-1}$ strain rate. Fractography was performed on the compressive fracture surfaces using Hitachi S4300 FESEM.

\section{Results}

\subsection{Macrostructural Characteristics}

No macropores or shrinkage cavities were observed in the cast monolithic and nanocomposite materials. No macrostructural defects were observed for extruded rods of monolithic and nanocomposite materials.

\subsection{Microstructural Characteristics}

Microstructural analysis results revealed that grain size and aspect ratio remained statistically unchanged in the case of nanocomposite as shown in Table 1 and Figures 1(a,b). CNT reinforcement distribution in the nanocomposite was reasonably uniform as shown in Figures 1(c,d).

Texture results are listed in Table $\mathbf{2}$ and shown in Figure 2. In monolithic and nanocomposite materials, the dominant texture in the transverse and longitudinal directions was $\left(\begin{array}{llll}1 & 0 & -1 & 1\end{array}\right)$.

\subsection{Hardness}

The results of microhardness measurements are listed in Table 1. The nanocomposite exhibited higher hardness than the monolithic material.

\subsection{Tensile Behavior}

The overall results of ambient temperature tensile testing of the extruded materials are shown in Table 3 and Figure 3(a). The strength, failure strain and work of fracture (WOF) of AZ31/AA5083/1.0 vol.\% CNT were higher compared to monolithic AZ31/AA5083. The WOF was determined by computing the area under the stress-strain

Table 1. Results of grain characteristics and microhardness of AZ31/AA5083 and AZ31/AA5083/CNT nanocomposite.

\begin{tabular}{|c|c|c|c|c|}
\hline \multirow{2}{*}{ Material } & \multirow{2}{*}{$\begin{array}{c}\text { CNT } \\
(\text { vol.\%) }\end{array}$} & \multicolumn{2}{|c|}{ Grain characteristics $^{a}$} & \multirow{2}{*}{$\begin{array}{c}\text { Microhardness } \\
\text { (HV) }\end{array}$} \\
\hline & & Size $(\mu \mathrm{m})$ & Aspect ratio & \\
\hline AZ31/AA5083 & - & $4.4 \pm 0.7$ & 1.4 & $114 \pm 6$ \\
\hline AZ31/AA5083/1.0 vol.\% CNT & 1.00 & $3.8 \pm 0.8$ & 1.4 & $137 \pm 7(+20)$ \\
\hline
\end{tabular}

Table 2. Texture results of AZ31/AA5083 and AZ31/AA5083/CNT nanocomposite based on X-ray diffraction.

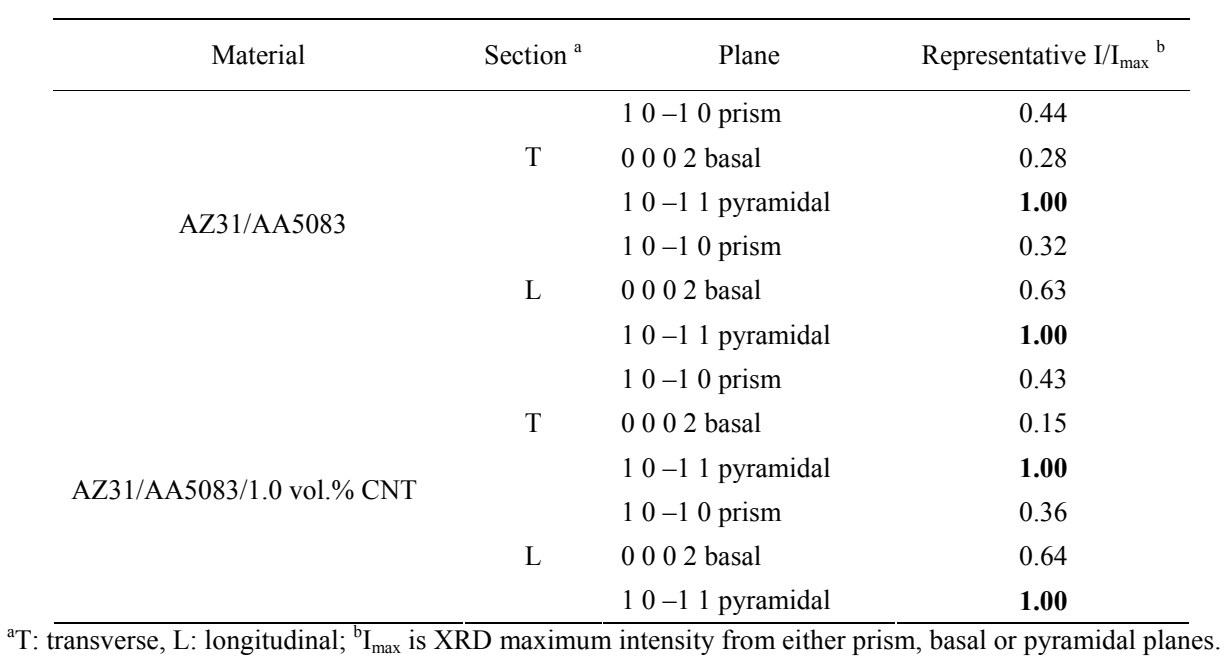


Table 3. Results of tensile testing of AZ31/AA5083 and AZ31/AA5083/CNT nanocomposite.

\begin{tabular}{ccccc}
\hline Material & $\begin{array}{c}0.2 \% \text { TYS } \\
(\mathrm{MPa})\end{array}$ & $\begin{array}{c}\text { UTS } \\
(\mathrm{MPa})\end{array}$ & $\begin{array}{c}\text { Failure Strain } \\
(\%)\end{array}$ & $\begin{array}{c}\mathrm{WOF} \\
\left(\mathrm{MJ} / \mathrm{m}^{3}\right)\end{array}$ \\
\hline AZ31/AA5083 & $203 \pm 4$ & $310 \pm 4$ & $8.7 \pm 1.8$ & $25 \pm 5$ \\
AZ31/AA5083/1.0 vol.\% CNT & $221 \pm 4(+9)$ & $321 \pm 1(+4)$ & $12.0 \pm 1.0(+38)$ & $36 \pm 4(+44)$
\end{tabular}
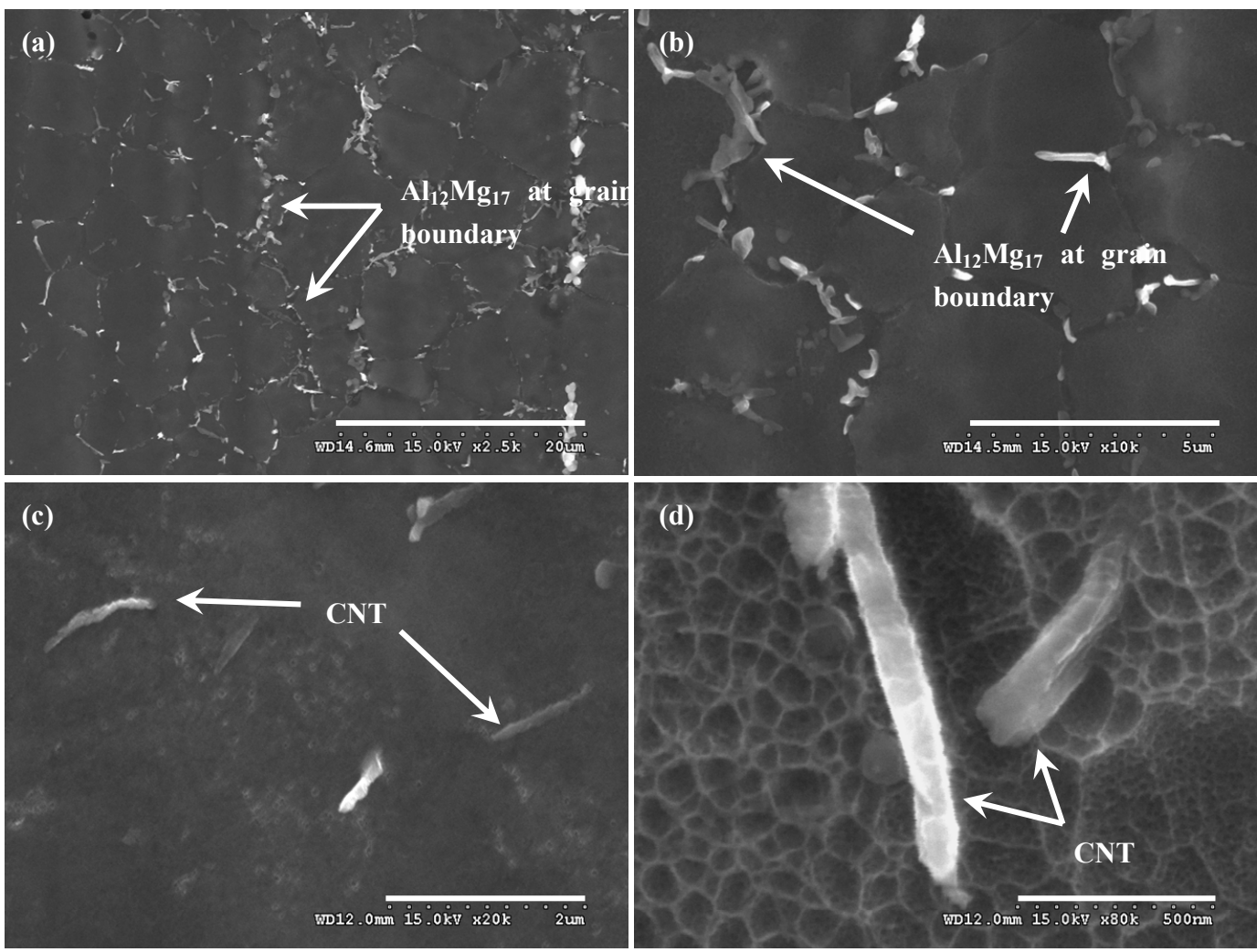

Figure 1. Representative micrographs showing grain size in monolithic AZ31/AA5083 and AZ31/AA5083/CNT nanocomposite: (a) Lower magnification and (b) Higher magnification. Representative micrographs showing individual CNT presence in the AZ31/AA5083/CNT nanocomposite: (c) Lower magnification and (d) Higher magnification.

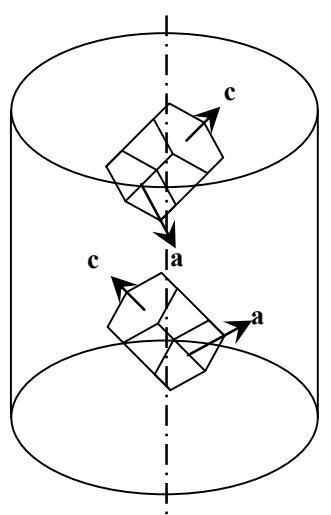

Figure 2. Schematic diagram showing textures of monolithic AZ31/AA5083 and AZ31/AA5083/CNT nanocomposite, based on X-ray diffraction. In each case, vertical axis (dashed line) is parallel to extrusion direction. Each cell is made up of 2 HCP units having 1 common $\left(\begin{array}{llll}0 & 0 & 0 & 2\end{array}\right)$ basal plane. curve up to the point of fracture. The fractured surface of all extruded materials exhibited mixed (ductile + brittle) mode of fracture as shown in Figures 4(a,b). Minimal CNT pull-out from the tensile fractured surface given the minimum CNT (vapor grown) aspect ratio of 100 [22] was observed in AZ31/AA5083/1.0 vol.\% CNT as shown in Figure 4(c).

\subsection{Compressive Behavior}

The overall results of ambient temperature compressive testing of the extruded materials are shown in Table 4 and Figure 3(b). The strength, failure strain and work of fracture (WOF) of AZ31/AA5083/1.0 vol.\% CNT were higher compared to monolithic AZ31/AA5083. The fractured surface of AZ31/AA5083/1.0 vol.\% CNT appeared smoother than that of monolithic AZ31/AA5083 as shown in Figures 4(d,e). CNT pull-out along the 

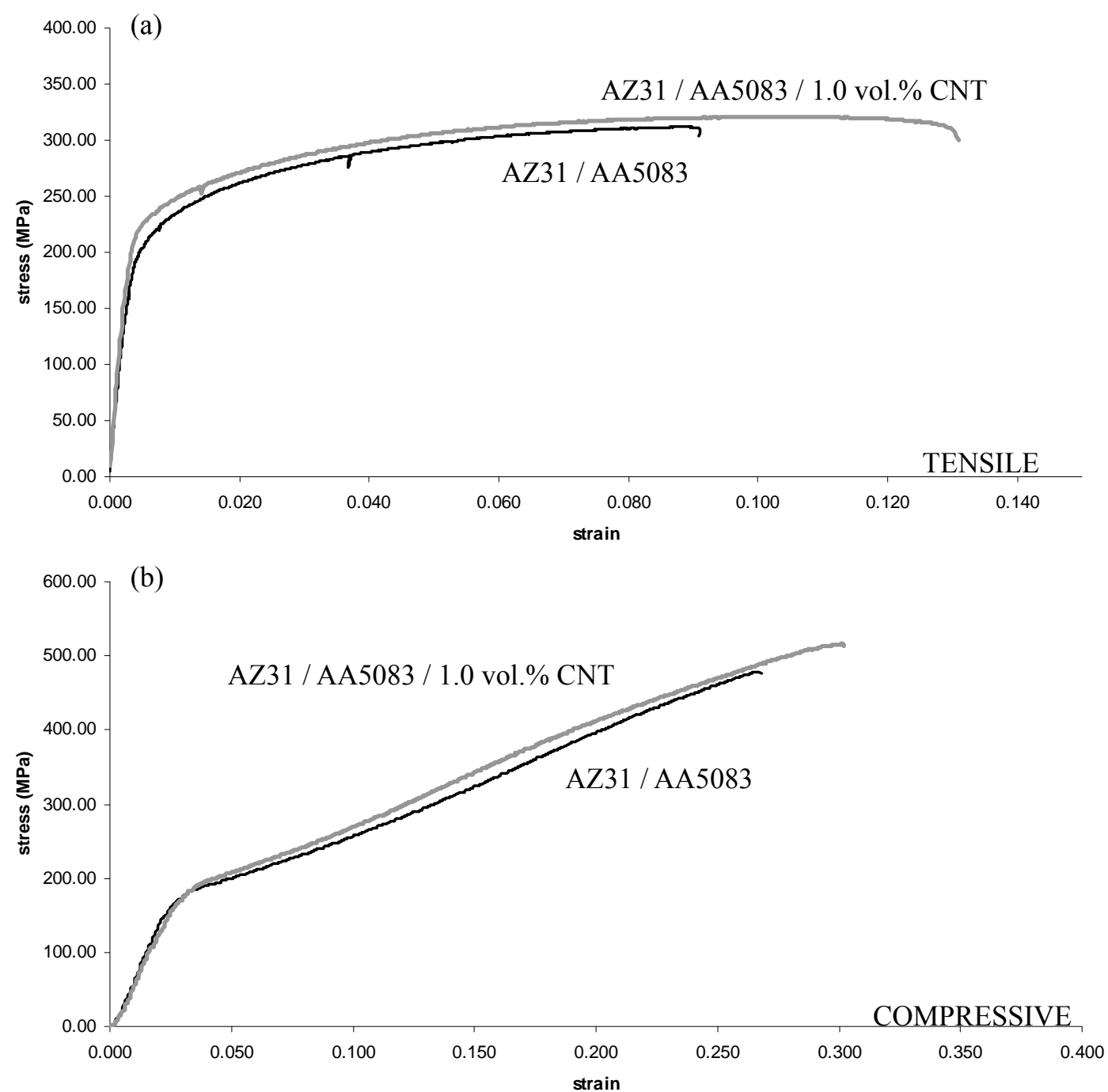

Figure 3. Representative: (a) Tensile and (b) Compressive stress-strain curves of monolithic AZ31/AA5083 and AZ31/AA5083/CNT nanocomposite.

Table 4. Results of compressive testing of AZ31/AA5083 and AZ31/AA5083/CNT nanocomposite.

\begin{tabular}{ccccc}
\hline Material & $\begin{array}{c}0.2 \% \mathrm{CYS} \\
(\mathrm{MPa})\end{array}$ & $\begin{array}{c}\text { UCS } \\
(\mathrm{MPa})\end{array}$ & $\begin{array}{c}\text { Failure Strain } \\
(\%)\end{array}$ & $\begin{array}{c}\mathrm{WOF} \\
\left(\mathrm{MJ} / \mathrm{m}^{3}\right)\end{array}$ \\
\hline AZ31/AA5083 & $141 \pm 8$ & $478 \pm 1$ & $19.9 \pm 1.8$ & $77 \pm 4$ \\
AZ31/AA5083/1.0 vol.\% CNT & $143 \pm 12(+1)$ & $512 \pm 6(+7)$ & $24.5 \pm 5.8(+23)$ & $95 \pm 6(+23)$ \\
\hline
\end{tabular}

compressive fractured surface was observed in AZ31/ AA5083/1.0 vol.\% CNT as shown in Figure 4(f).

\section{Discussion}

\subsection{Synthesis of Monolithic AZ31/AA5083 and AZ31/AA5083/CNT Nanocomposite}

Synthesis of monolithic and nanocomposite materials, the final form being extruded rods, was successfully accomplished with: 1) No detectable metal oxidation and 2)
No detectable reaction between graphite crucible and melts. The inert atmosphere used during DMD was effective in preventing oxidation of the $\mathrm{Mg}$ melt. No stable carbides of $\mathrm{Mg}$ or $\mathrm{Al}$ formed due to reaction with graphite crucible.

\subsection{Microstructural Characteristics}

Microstructural characterization of extruded samples is discussed in terms of: 1) Grain characteristics and 2) 

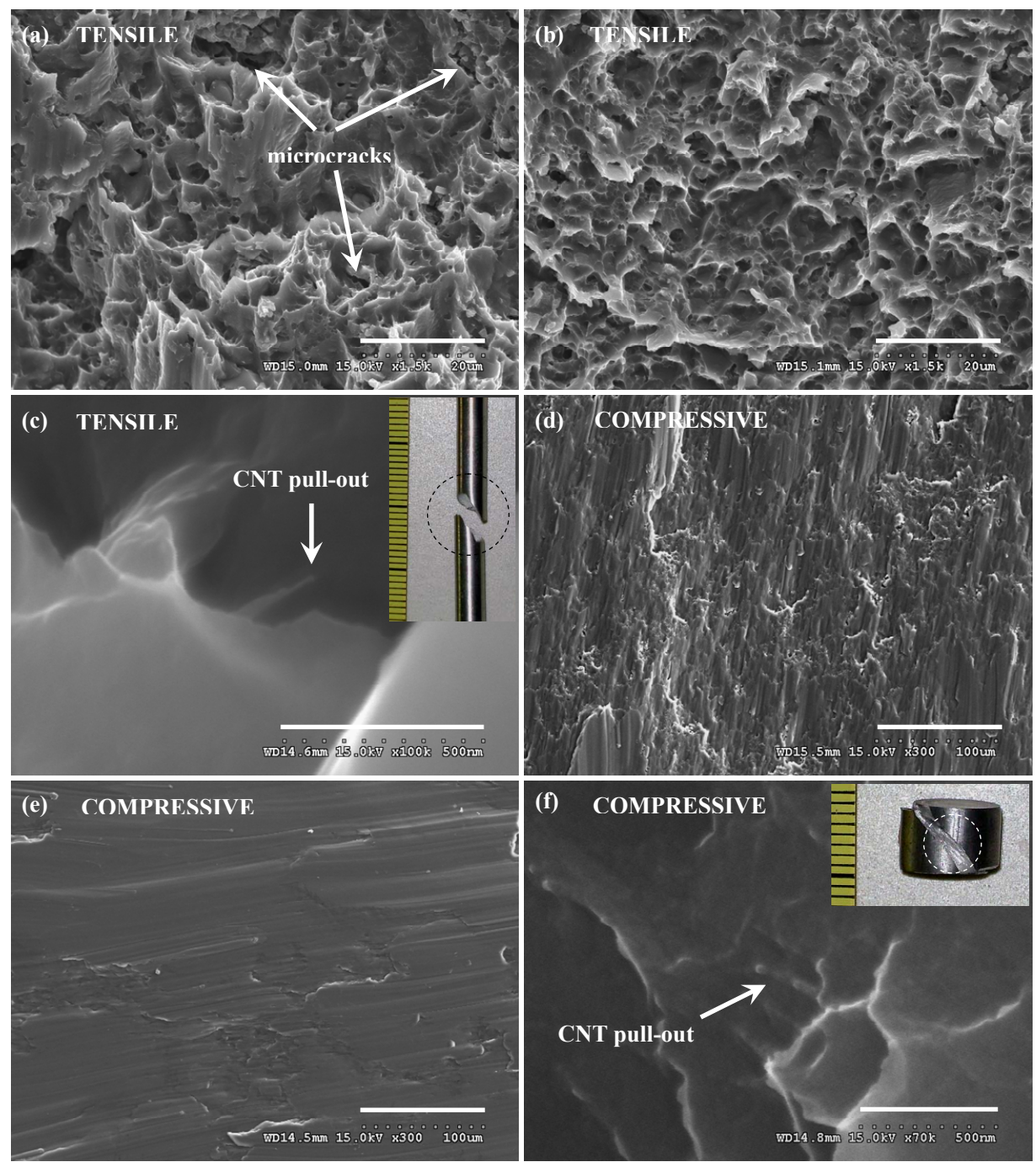

Figure 4. Representative tensile fractographs of: (a) Monolithic AZ31/AA5083, (b) AZ31/AA5083/CNT nanocomposite and (c) Pull-out in AZ31/AA5083/CNT nanocomposite. Representative compressive fractographs of: (d) Monolithic AZ31/AA5083, (e) AZ31/AA5083/CNT nanocomposite and (f) Pull-out in AZ31/AA5083/CNT nanocomposite. Insets in (c) and (f) show tensile and compressive fractured samples, respectively.

CNT reinforcement distribution.

Nearly equiaxed grains were observed in monolithic material and nanocomposite as shown in Table $\mathbf{1}$ and Figures 1(a,b). Grain size was statistically insignificant in the case of nanocomposite, suggesting the inability of CNT to serve as either nucleation sites or obstacles to grain growth during solid state cooling. It was observed that $\beta-\mathrm{Al}_{12} \mathrm{Mg}_{17}$ intermetallic particles decorated the grain boundaries in the monolithic material and nanocomposite (X-ray diffraction (XRD) analysis revealed the presence of $\beta-\mathrm{Al}_{12} \mathrm{Mg}_{17}$ phase [24]).

The reasonably uniform distribution of CNT as shown in Figures 1(c,d) can be attributed to: 1) Minimal gravity-associated segregation due to judicious selection of stirring parameters [20], 2) Good wetting of CNT nanoparticles by the alloy matrix [25-28], 3) Argon gas disintegration of metallic stream [29], and 4) Dynamic deposition of composite slurry on substrate followed by hot extrusion. Similar reasonably uniform distribution of CNT nanoparticles in magnesium alloy AZ31 has also been recently reported [28].

\subsection{Mechanical Behavior}

\subsubsection{Hardness}

A significant increase in microhardness by $20 \%$ was observed in the nanocomposite when compared to monolithic material as listed in Table 1. This was consistent with earlier observations made on $\mathrm{Mg} / \mathrm{Al}_{2} \mathrm{O}_{3}, \mathrm{AZ31} / \mathrm{C}_{60}$ and AZ31/MWCNT nanocomposites [30-32]. The increase in hardness of the nanocomposite in the present 
study can be attributed to: 1) Reasonably uniform distribution of harder CNT in the matrix and 2) Higher constraint to localized matrix deformation during indentation due to the presence of nanoparticles $[30,31,33]$.

\subsubsection{Tensile and Compressive Behavior}

\subsubsection{Strength}

The tensile and compressive strengths of monolithic material and nanocomposite are listed in Tables 3 and 4 (and shown in Figures 3(a,b)), respectively. 0.2\%TYS and UTS were enhanced by $9 \%$ and $4 \%$, respectively, in AZ31/AA5083/1.0 vol.\% CNT compared to monolithic material. In comparison of compressive strengths, $0.2 \%$ CYS and UCS of AZ31/AA5083/1.0 vol.\% CNT were higher (by $1 \%$ and $7 \%$, respectively) compared to monolithic AZ31/AA5083. The stress detected at almost any given strain was higher for AZ31/AA5083/1.0 vol.\% CNT compared to monolithic AZ31/AA5083 as shown in Figure 3(b). The tensile/compressive strength increase in AZ31/AA5083/1.0 vol.\% CNT compared to monolithic AZ31/AA5083 can be attributed to the following well known factors (pertaining to reinforcement): 1) Dislocation generation due to elastic modulus mismatch and coefficient of thermal expansion mismatch between the matrix and reinforcement [30,33-35], 2) Orowan strengthening mechanism [34-36] and 3) Load transfer from matrix to reinforcement $[30,34]$. The tensile/compressive strength increase in AZ31/AA5083/1.0 vol.\% CNT compared to monolithic AZ31/AA5083 was despite compressive shear buckling of CNT in AZ31/AA5083/ 1.0 vol.\% CNT as illustrated in Figure 5. Here, the CNT (with aspect ratio as high as 100 [22]) is prone to buckling followed by fracture within the AZ31/AA5083 matrix during compressive deformation [37-39]. CNT buckling within the AZ31/AA5083 matrix occurs more easily with increasing CNT aspect ratio (or slenderness ratio) $[39,40]$. This induces a significantly lower limit on the well known factors pertaining to reinforcement just listed.

In monolithic AZ31/AA5083, 0.2\%TYS was about 1.44 times the $0.2 \%$ CYS. Here, the tensile/compressive yield stress anisotropy was despite the similarity in crystallographic texture compared to monolithic AZ31/ AA5083, where $\left\{\begin{array}{lllllll}1 & 0 & 1 & -2\end{array}\right\}<1 \quad 0 \quad 1-1>$-type twinning was activated along the c-axis of the HCP unit cell in Figure 2 with comparatively similar ease in both tension and compression along the c-axis, based on the $45^{\circ}$ angle between the c-axis and the vertical axis [41, 42]. The tensile/compressive yield stress anisotropy can be attributed generally to half the strain rate used (less strain hardening) in compressive testing compared to tensile testing. In AZ31/AA5083/1.0 vol.\% CNT nanocomposite, $0.2 \%$ TYS was about 1.55 times the $0.2 \%$ CYS (slightly higher ratio compared to monolithic AZ31/AA5083). Here, the slightly increased tensile/compressive yield stress anisotropy can be attributed to compressive shear buckling of CNT as illustrated in Figure 5. The CNT is prone to buckling followed by fracture within the AZ31/AA5083 matrix during compressive deformation unlike during tensile deformation [37-40].

\subsubsection{Failure Strain}

The tensile and compressive failure strains of monolithic material and nanocomposite are listed in Tables 3 and $\mathbf{4}$ (and shown in Figures 3(a,b)), respectively. Compared to monolithic material, tensile and compressive failure strains were enhanced by $38 \%$ and $23 \%$ (respectively) in AZ31/AA5083/1.0 vol.\% CNT. The failure strain increase in AZ31/AA5083/1.0 vol.\% CNT compared to monolithic AZ31/AA5083 can be attributed to the following factors pertaining to reinforcement: 1) Presence and reasonably uniform distribution of CNT nanoparticles [31,43] and 2) Compressive shear buckling of CNT (regarding compressive failure strain only) [37-40]. In the case of reasonably uniform distribution of CNT nano-
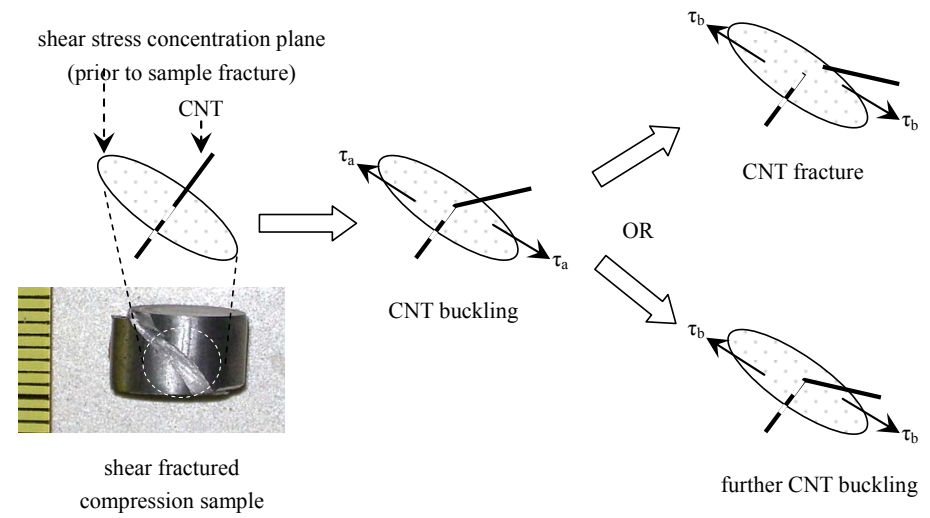

Figure 5. Schematic diagram illustrating compressive shear buckling of CNT in AZ31/AA5083/CNT nanocomposite ( $\tau_{\mathrm{a}}$ and $\tau_{\mathrm{b}}$ are planar shear stresses where $\tau_{\mathrm{a}}<\tau_{\mathrm{b}}$ ). 
particles, it has been shown in previous studies that nanoparticles provide sites where cleavage cracks are opened ahead of the advancing crack front. This: 1) dissipates the stress concentration which would otherwise exist at the crack front and 2) alters the local effective stress state from plane strain to plane stress in the neighbourhood of crack tip [31,43]. In the case of compressive shear buckling of CNT, CNT buckling within the AZ31/AA5083 matrix aids in dispersing localized stored energy during compressive deformation. This allows AZ31/AA5083/1.0 vol.\% CNT to globally absorb relatively large amounts of strain energy during compressive deformation [37-40]. Here, CNT buckling within the AZ31/AA5083 matrix is a compressive toughening mechanism. Tensile fracture behaviour of both monolithic material and nanocomposite was mixed (ductile + brittle) as shown in Figures $4(\mathbf{a}, \mathbf{b})$. However, the tensile fractured surface of the nanocomposite had: 1) Higher occurrence of smaller dimple-like features and 2) Absence of microcracks, compared to that of monolithic material. The tensile cavitation resistance was lower in the nanocomposite compared to monolithic material. For AZ31/AA5083/1.0 vol.\% CNT, compressive fracture behavior based on viscoplastic flow [44] was relatively more ductile (smoother fracture surface exhibited) compared to monolithic AZ31/AA5083 as shown in Figures 4(d,e). This relatively more ductile compressive fracture behavior can be attributed to increase in shear band spacing $[44,45]$.

\subsubsection{Work of Fracture}

The tensile and compressive work of fracture (WOF) of monolithic material and nanocomposite are listed in Tables 3 and 4 (and illustrated in Figures 3(a,b)), respectively. WOF quantified the ability of the material to absorb energy up to fracture under load [46]. Compared to monolithic material, tensile and compressive WOF were enhanced by $44 \%$ and $23 \%$ (respectively) in AZ31/AA5083/1.0 vol.\% CNT. The high increments in tensile and compressive WOF exhibited by AZ31/AA 5083/1.0 vol.\% CNT show its potential to be used in damage tolerant design.

\section{Conclusions}

1) Monolithic AZ31/AA5083 hybrid alloy and AZ31/AA 5083/1.0 vol.\% CNT hybrid alloy nanocomposite can be successfully synthesized using the DMD technique followed by hot extrusion.

2) Compared to monolithic AZ31/AA5083, tensile and compressive strengths of AZ31/AA5083/1.0 vol\% CNT were enhanced. This can be attributed to well known factors pertaining to reinforcement despite compressive shear buckling of CNT (regarding compressive strength only).

3) Compared to monolithic AZ31/AA5083, tensile and compressive failure strains of AZ31/AA5083/1.0 vol.\% CNT were enhanced. This can be attributed to the following factors pertaining to reinforcement: (a) Presence and reasonably uniform distribution of CNT nanoparticles and (b) Compressive shear buckling of CNT (regarding compressive failure strain only).

4) Compared to monolithic AZ31/AA5083, AZ31/AA 5083/1.0 vol.\% CNT exhibited high increments in both tensile and compressive WOF.

\section{Acknowledgements}

Authors wish to acknowledge National University of Singapore (NUS) and Temasek Defence Systems Institute (TDSI) for funding this research (TDSI/09-011/1A and WBS\# R265000349).

\section{REFERENCES}

[1] Y. Morisada, H. Fujii, T. Nagaoka and M. Fukusumi, "Effect of Friction Stir Processing with SiC Particles on Microstructure and Hardness of AZ31," Materials Science and Engineering A, Vol. 433, 2006, pp. 50-54. doi:10.1016/j.msea.2006.06.089

[2] Y. Morisada, H. Fujii, T. Nagaoka and M. Fukusumi, "Nanocrystallized Magnesium Alloy-Uniform Dispersion of $\mathrm{C}_{60}$ Molecules," Scripta Materialia, Vol. 55, 2006, pp. 1067-1070.

doi:10.1016/j.scriptamat.2006.07.055

[3] Y. Morisada, H. Fujii, T. Nagaoka and M. Fukusumi, "MWCNTs/AZ31 Surface Composites Fabricated by Friction Stir Processing," Materials Science and Engineering A, Vol. 419, 2006, pp. 344-348. doi:10.1016/j.msea.2006.01.016

[4] W. B. Ding, H. Y. Jiang, X. Q. Zeng, D. H. Li and S.S. Yao, "The Surface Modified Composite Layer Formation with Boron Carbide Particles on Magnesium Alloy Surfaces Through Pulse Gas Tungsten Arc Treatment," Applied Surface Science, Vol. 253, No. 8, 2007, pp. 3877 -3883 . doi:10.1016/j.apsusc.2006.08.015

[5] W. B. Ding, H. Y. Jiang, X. Q. Zeng, D. H. Li and S. S. Yao, "The Properties of Gas Tungsten Arc Deposited $\mathrm{SiC}_{\mathrm{P}}$ and $\mathrm{Al}$ Surface Coating on Magnesium Alloy AZ31," Materials Letters, Vol. 61, No. 2, 2007, pp. 496 -501 .

doi:10.1016/j.matlet.2006.04.113

[6] W .B. Ding, H. Y. Jiang, X. Q. Zeng, D. H. Li and S. S. Yao, "Microstructure and Mechanical Properties of GTA Surface Modified Composite Layer on Magnesium Alloy AZ31 with $\mathrm{SiC}_{\mathrm{P}}$," Journal of Alloys and Compounds, Vol. 429, No. 1-2, 2007, pp. 233-241. doi:10.1016/i.jallcom.2006.03.083

[7] K. Mizuuchi, K. Inoue, K. Hamada, M. Sugioka, M. Itami, M. Fukusumi and M. Kawahara, "Processing of TiNi SMA Fiber Reinforced AZ31 Mg Alloy Matrix Compos- 
ite by Pulsed Current Hot Pressing," Materials Science and Engineering A, Vol. 367, No. 1-2, 2004, pp. 343-349. doi:10.1016/j.msea.2003.10.286

[8] R. F. Service, "Superstrong Nanotubes Show They are Smart too," Science, Vol. 281, 1998, pp. 940-942. doi:10.1126/science.281.5379.940

[9] P. G. Collins and P. Avouris, "Nanotubes for Electronics," Scientific American, Vol. 283, No. 6, 2000, pp. $38-45$. doi:10.1038/scientificamerican1200-62

[10] Y. Min-Feng, B. S. Files, S. Arepalli and R. S. Rouff, "Tensile Loading of Ropes of Single Wall Carbon Nanotubes and Their Mechanical Properties," Physical Review Letters, Vol. 84, No. 24, 2000, pp. 5552-5555. doi:10.1103/PhysRevLett.84.5552

[11] W. H. Knechtel, G. S. Dusberg, W. J. Blau, E. Hernandez and A. Rubio, "Reversible Bending of Carbon Nanotubes Using a Transmission Electron Microscope," Applied Physical Letters, Vol. 73, No. 14, 1998, pp. 1961-1963. doi:10.1063/1.122335

[12] P. G. Collins, M. S. Arnold and P. Avouris, "Engineering Carbon Nanotubes and Nanotube Circuits Using Electrical Breakdown," Science, Vol. 292, 2001, pp. 706-709. doi:10.1126/science.1058782

[13] H. Stahl, J. Appenzeller, R. Martel, P. Avouris and B. Lengeler, "Intertube Coupling in Ropes of Single-Wall Carbon Nanotubes," Physical Review Letters, Vol. 85, No. 26, 2000, pp. 5186-5189. doi:10.1103/PhysRevLett.84.4613

[14] S. Berber, Y. K. Kwon and D. Tomanek, "Unusually High Thermal Conductivity of Carbon Nanotubes," Physical Review Letters, Vol. 84, No. 20, 2000, pp. 4613-4616. doi:10.1103/PhysRevLett.84.4613

[15] K. K. H. Wong, M. Zinke-Allmang, J. L. Hutter, S. Hrapovic, J.H.T. Luong and W. Wan, "The Effect of Carbon Nanotube Aspect Ratio and Loading on the Elastic modulus of Electrospun Poly (Vinyl Alcohol)-Carbon Nanotube Hybrid Fibers," Carbon, Vol. 47, 2009, pp. 2571-2578. doi:10.1016/j.carbon.2009.05.006

[16] P. Chen, X. Wu, J. Lin and K. L. Tan, "Synthesis of $\mathrm{Cu}$ Nanoparticles and Microsized Fibers by Using Carbon Nanotubes as a Template," Journal of Physical Chemistry B, Vol. 103, 1999, pp. 4559-4561. doi:10.1021/jp983983j

[17] X. Chen, J. Xia, J. Peng, W. Li and S. Xie, "CarbonNanotube Metal-Matrix Composites Prepared by Electroless Plating," Composites Science and Technology, Vol. 60,2000 , pp. $301-306$. doi:10.1016/S0266-3538(99)00127-X

[18] J. N. Coleman, S. Curran, A. B. Dalton, A. P. Harvey, B. McCarthy, W. Blau and R. C. Barklie, "PercolationDominated Conductivity in a Conjugated-Polymer-CarbonNanotube Composite," Physical Review B, Vol. 58, 1998, pp. R7492-R7495. doi:10.1103/PhysRevB.58.R7492
[19] V. Lordi and N. Yao, "Molecular Mechanics of Binding in Carbon-Nanotube-Polymer Composites," Journal of Materials Research, Vol. 15, No. 12, 2000, pp. 2770 -2779 . doi:10.1557/JMR.2000.0396

[20] L. M. Tham, M. Gupta and L. Cheng, "Influence of Processing Parameters during Disintegrated Melt Deposition Processing on Near Net Shape Synthesis of Aluminium Based Metal Matrix Composites," Materials Science and Technology, Vol. 15, 1999, pp. 1139-1146.

[21] M. Gupta, M. O. Lai and S. C. Lim, "Regarding the Processing Associated Microstructure and Mechanical Properties Improvement of an Al-4.5Cu Alloy," Journal of Alloys and Compounds, Vol. 260, 1997, pp. 250-255. doi:10.1016/S0925-8388(97)00156-4

[22] M. H. Al-Saleh and U. Sundararaj, "A Review of Vapor Grown Carbon Nanofiber/Polymer Conductive Composites," Carbon, Vol. 47, No. 1, 2008, pp. 2-22. doi:10.1016/j.carbon.2008.09.039

[23] M. M. Avedesian and H. Baker, "ASM Specialty Handbook: Magnesium and Magnesium Alloys," ASM International $^{\circledR}$, Novelty, 1999.

[24] Q. B. Nguyen and M. Gupta, "Increasing Significantly the Failure Strain and Work of Fracture of Solidification Processed AZ31B Using Nano- $\mathrm{Al}_{2} \mathrm{O}_{3}$ Particulates," Journal of Alloys and Compounds, Vol. 459, 2007, pp. 244-250. doi:10.1016/j.jallcom.2007.05.038

[25] B. Q. Han and D. C. Dunand, "Microstructure and Mechanical Properties of Magnesium Containing High Volume Fractions of Yttria Dispersoids," Materials Science and Engineering A, Vol. 277, 2000, pp. 297-304. doi:10.1016/S0921-5093(99)00074-X

[26] N. Eustathopoulos, M. G. Nicholas and M. Drevet, "Wettability at High Temperatures," Pergamon, London, 1997.

[27] J. D. Gilchrist, "Extraction Metallurgy," Pergamon, London, 1989.

[28] M. Paramsothy, S. F. Hassan, N. Srikanth and M. Gupta, "Adding Carbon Nanotubes and Integrating with AA5052 Aluminium Alloy Core to Simultaneously Enhance Stiffness, Strength and Failure Strain of AZ31 Magnesium Alloy," Composites Part A, Vol. 40, 2009, pp. 1490 -1500 . doi:10.1016/j.compositesa.2009.06.007

[29] M. Gupta, M. O. Lai and C. Y. Soo, "Effect of Type of Processing on the Microstructural Features and Mechanical Properties of A1-Cu/SiC Metal Matrix Composites," Materials Science and Engineering A, Vol. 210, 1996, pp. 114-122. doi:10.1016/0921-5093(95)10077-6

[30] S. F. Hassan and M. Gupta, "Effect of Different Types of Nano-Size Oxide Particulates on Microstructural and Mechanical Properties of Elemental Mg," Journal of Materials Science, Vol. 41, 2006, pp. 2229-2236. doi:10.1007/s10853-006-7178-3

[31] S. F. Hassan and M. Gupta, "Effect of Particulate Size of $\mathrm{Al}_{2} \mathrm{O}_{3}$ Reinforcement on Microstructure and Mechanical 
Behavior of Solidification Processed Elemental Mg," Journal of Alloys and Compounds, Vol. 419, 2006, pp. 84-90. doi:10.1016/j.jallcom.2005.10.005

[32] S. F. Hassan and M. Gupta, "Enhancing Physical and Mechanical Properties of $\mathrm{Mg}$ Using Nanosized $\mathrm{Al}_{2} \mathrm{O}_{3}$ Particulates as Reinforcement," Metallurgical and Materials Transactions A, Vol. 36, No. 8, 2005, pp. 2253 -2258 . doi:10.1007/s11661-005-0344-4

[33] C. S. Goh, J. Wei, L. C. Lee and M. Gupta, "Development of Novel Carbon Nanotube Reinforced Magnesium Nanocomposites Using the Powder Metallurgy Technique," Nanotechnology, Vol. 17, 2006, pp. 7-12. doi:10.1088/0957-4484/17/1/002

[34] Z. Szaraz, Z. Trojanova, M. Cabbibo and E. Evangelista, "Strengthening in a WE54 Magnesium Alloy Containing SiC Particles," Materials Science and Engineering A, Vol. 462, 2007, pp. 225-229. doi:10.1016/j.msea.2006.01.182

[35] L. H. Dai, Z. Ling and Y. L. Bai, "Size-Dependent Inelastic Behavior Of Particle-Reinforced Metal-Matrix Composites," Composites Science and Technology, Vol. 61, 2001, pp. 1057-1063. doi:10.1016/S0266-3538(00)00235-9

[36] D. Hull and D. J. Bacon, "Introduction to Dislocations", Butterworth-Heinemann, Oxford, 2002.

[37] E. T. Thostenson and T. -W. Chou, "Nanotube Buckling in Aligned Multi-Wall Carbon Nanotube Composites," Carbon, Vol. 42, 2004, pp. 3003-3042. doi:10.1016/j.carbon.2004.06.012

[38] S. Namilae and N. Chandra, "Role of Atomic Scale Interfaces in the Compressive Behavior of Carbon Nanotubes in Composites," Composites Science and Technology, Vol. 66, 2006, pp. 2030-2038. doi:10.1016/j.compscitech.2006.01.009

[39] M. Paramsothy, J. Chan, R. Kwok and M. Gupta, "Addition of CNTs to Enhance Tensile/Compressive Response of Magnesium Alloy ZK60A," Composites Part A, Vol.
42, No. 2, 2010, pp. 180-188. doi:10.1016/j.compositesa.2010.11.001

[40] J.-M. Lu, C.-C. Hwang, Q.-Y. Kuo and Y.-C. Wang, "Mechanical Buckling of Multi-Walled Carbon Nanotubes: The Effects of Slenderness Ratio," Physica E, Vol. 40, 2008, pp. 1305-1308. doi:10.1016/j.physe.2007.08.120

[41] T. Laser, C. Hartig, M. R. Nurnberg, D. Letzig and R. Bormann, "The Influence of Calcium and Cerium Mischmetal on the Microstructural Evolution of Mg-3Al-1Zn during Extrusion and Resulting Mechanical Properties," Acta Materialia, Vol. 56, 2008, pp. 2791-2798. doi:10.1016/j.actamat.2008.02.010

[42] J. Bohlen, S. B. Yi, J. Swiostek, D. Letzig, H. G. Brokmeier and K. U. Kainer, "Microstructure and Texture Development during Hydrostatic Extrusion of Magnesium Alloy AZ31," Scripta Materialia, Vol. 53, 2005, pp. 259-264. doi:10.1016/j.scriptamat.2005.03.036

[43] S. F. Hassan and M. Gupta, "Development of Nano- $\mathrm{Y}_{2} \mathrm{O}_{3}$ Containing Magnesium Nanocomposites Using Solidification Processing," Journal of Alloys and Compounds, Vol. 429, 2007, pp. 176-183. doi:10.1016/j.jallcom.2006.04.033

[44] R. C. Batra and Z. G. Wei, "Instability Strain and Shear Band Spacing in Simple Tensile/Compressive Deformations of Thermoviscoplastic Materials," International Journal of Impact Engineering, Vol. 34, 2007, pp. 448-463.

doi:10.1016/i.ijimpeng.2005.11.004

[45] T. S. Wang, R. J. Hou, B. Lv, M. Zhang and F. C. Zhang, "Microstructure Evolution and Deformation Mechanism Change in $0.98 \mathrm{C}-8.3 \mathrm{Mn}-0.04 \mathrm{~N}$ Steel during Compressive Deformation," Materials Science and Engineering A, Vol. 465, 2007, pp. 68-71. doi:10.1016/j.msea.2007.02.065

[46] R. E. Reed-Hill, "Physical Metallurgy Principles," D Van Nostrand Company, Princeton, 1964. 